\title{
Report on the 2017 Paediatric Colorectal Conference
}

Timothy Jumbi ${ }^{1}$, Swaleh Shahbal ${ }^{1}$,Francis Osawa ${ }^{1}$, Joel Lessan ${ }^{2}$

1. School of Medicine, University of Nairobi

2. Department of Surgery, Kenyatta National Hospital

Correspondence to:Timothy Mwai Jumbi, P.O. Box 19762 - 00202, Nairobi, Kenya. E-mail: mwaitim@gmail.com

Key words: Colorectal Conference, Kenya, Paediatric

Surgeons, Anorectal Malformation

Ann Afr Surg. 2018;15(2):48-51

DOI:http://dx.doi.org/10.4314/aas.v15i2.3

\section{Conflicts of Interest: None}

Funding: None

(C) 2018 Author. This work is licensed under the

Creative Commons Attribution 4.0 International

License.

\section{Background}

The Kenya Association of Paediatric Surgeons (KAPS) in collaboration with the Kenyatta National Hospital $(\mathrm{KNH})$ and the University of Nairobi (UON) organized a colorectal conference on $6^{\text {th }}-11^{\text {th }}$ November2017. The theme of the conference was "Demystifying Anorectal malformations (ARM). There is Hope!" The main objective for the conference was to create awareness on the existence of ARM and its management with an aim of providing hope of care to the affected children and their families.

\section{Situation Analysis}

The pediatric surgical department in Kenyatta National Hospital is the main referral center for patients with ARM. ARM cases represent approximately $40 \%$ of total admissions annually most of which are referrals from peripheral facilities.(1) The challenges facing management of these conditions in Africa include delayed diagnosis and presentation, inadequate access to health facilities, limited number of pediatric surgeons, lack of standard management protocols and poor post-surgical follow-up. (2, 3)The above challenges formed the basis of the conference theme with an aim to demystify the condition to both the parents and the health professionals managing ARM.

\section{Discussion and Training Activities}

The conference was designed to include a surgical workshop and a seminar. The surgical workshop took place for five days and was held in the main pediatric

surgical theater of the Kenyatta National Hospital.

The seminar was a single day event which took place at The Nairobi Hospital Anderson Convection Center.

In line with the conference objective, the event was aired on one of the national TV stations. The short documentary included interviews of mothers with children born with ARMs who shared their experiences in dealing with the condition. In addition to publicizing the conference, this documentary was also used by the surgeons as an avenue of educating the public on ARM, its diagnosis and management. (4)

\section{The participants}

There were a total of 72 participants who attended the conference. The cadre of the delegate attendees consisted of pediatric surgeons, general surgeons, pediatric anaesthesiologists, pediatricians, medical officers, nurses and residents in surgery and anesthesia.

This delegation included representatives from the University of Nairobi, Kenyatta National Hospital, AIC Kijabe Mission Hospital, Kenyatta University, Coast General Hospital, Moi Teaching and Referral Hospital and the Aga Khan University Hospital.

The trainers were recruited from the faculties of pediatric surgery in the represented institutions who form the membership body of the Kenya Association of Peadiatric Surgeons. They are pediatric surgeons with experience in colorectal surgery, urology, neonatal surgery and laparoscopic surgery (Table 1).

Insert table 1 here 


\section{The Workshop}

The 5 day surgical workshop had three main sessions which included a morning lecture session, a practical surgical demonstration session with live video coverage with commentary and an interactive question and answer session after the surgical demonstration. The main topics covered in the workshop session included; Initial Management of ARM; Anaesthetic considerations in ARM patients; Surgical anatomy and principles of repair of ARM; Laparoscopic considerations in ARM and Post-operative outcomes after ARM surgery.

There were a total of 12 patients who underwent surgery during the surgical sessions. The children were pre-selected by the event facilitators to include various variants of ARM, these included: ARM with no fistula; ARM with Recto-vestibular fistula, recto-perineal fistula, recto- urethral fistula, bucket handle deformities and cloacal malformations. The training sessions included live surgical demonstrations of different repair techniques including: primary anoplasty, anterior saggitalanorectoplasty(ASARP),

posterior saggitalanorectoplasty (PSARP) and laparoscopic assisted anorectoplasty.

Notably, Dr. Lessan gave an in-depth demonstration on the fashioning of a divided sigmoid colostomy as the first stage of surgery in most of ARM patients. Dr. Kambuni demonstrated the steps of a primary anoplasty and highlighted the indications and advantages of this form of single stage repair over the staged repair for ARM. Dr. Muma and Dr. Kuria demonstrated the principles of the laparoscopic assisted anorectoplasty and emphasized that patient selection is key in determining a favorable outcome for this form of repair. The anesthetic principles surrounding the ARM patient were covered by Dr. Nabulindo and the focus was mainly on pain management and regional anesthesia. A procedural demonstration on caudal block was carried out on the patients prior to surgery.

\section{The Seminar}

The seminar had 4 main sessions moderated by the association members with presenters who led discussions on research papers and updates in management of ARM. The topics covered included:
History of ARM; advances in embryology and anatomy of ARM; the role of imaging in ARM; anesthesia of the ARM patient; Colostomy care for the ARM patient; the role of laparoscopy in ARM; outcome of ARM surgery in Kenya; new advances in management of ARM and the social challenges of patients with ARM.

Prof. Kyambi gave a detailed description on the History of ARM; the talk was both educative and inspirational as he gave the sequences in the evolution of the management of ARM in Africa and the related social stigma that has since transformed in these present times. The discussion on the social aspects of ARM was reiterated by the nursing team led by Mrs. Ngugi and Mrs. Ndungu who moderated a debate on the challenges faced by families affected with ARM which include but not limited to social discrimination and poverty.

Dr. Trudea gave updates on the imaging practices in ARM specifically the utility of transperineal ultrasound in determining the pouch to perineum distance while evaluating ARM defects; this modality was recommended an affordable and feasible alternative that would reduce the radiation exposure to children which normally occurs with the commonly used pressure colostogram. (5)

D. Shahbal was keen to highlight that $72 \%$ of patients with ARM operated in $\mathrm{KNH}$ had good functional outcome while redo surgeries accounted for majority of poor outcomes. The redo surgeries are commonly due to complications such as ectopic neoanus, anal strictures and mucosal prolapse. He also emphasized on the utility of ASARP which has been shown to be a technically easier repair for the vestibular and perineal fistula variants of ARM. (1)

\section{Recommendations and Action Plan}

Recommendations were compiled and discussed with the delegates and it was agreed that execution be taken up by the participants and association members, thereafter an action plan was formulated to improve advocacy and awareness of ARM and to facilitate the implementation of the management principles in ARM.

The action plan was geared towards an ARM working group that would be tasked in the development and implementation of guidelines in ARM management. It was recommended that a support group be formed that 
would include family members with children born with ARM and family of children who have undergone repair Table 1: List of Faculty

\section{Description}

Name

\begin{tabular}{|c|c|}
\hline Prof. J. Kyambi & $\begin{array}{l}\text { First trained pediatric surgeon in Kenya, } \\
\text { founder pediatric surgery program\& } \\
\text { faculty member in the UON }\end{array}$ \\
\hline Dr. Joel Lessan & $\begin{array}{l}\text { Pediatric surgeon, Head of department in } \\
\text { Specialized Surgical Services in } \mathrm{KNH} \\
\text { \&chairman of KAPS }\end{array}$ \\
\hline Dr. Francis Osawa & $\begin{array}{l}\text { Consultant pediatric surgeon and } \\
\text { Urologist, lecturer of Surgery in the UON } \\
\text { \& current secretary of KAPS }\end{array}$ \\
\hline Dr. Fred Kambuni & $\begin{array}{l}\text { Consultant pediatric surgeon and } \\
\text { urologist\& Head of pediatric surgical unit }\end{array}$ \\
\hline
\end{tabular}

Dr. J.M. Ndungu Consultant pediatric surgeon and lecturer $\&$ thematic unit head of pediatric surgery in the UON

Dr. Hamdun Said Consultant general and pediatric surgeon at the $\mathrm{KNH}$

Dr. KihikoKuria consultant pediatric surgeon, lecturer in the UON \&specialist in pediatriclaparoscopy surgery

Dr. Erik Hansen Pediatric surgeon from Alabama, head of Pediatric surgical unit in AIC Kijabe Mission Hospital \& surgeon of the Bethany kids program

$\begin{array}{ll}\text { Dr. Ken Muma } & \begin{array}{l}\text { Pediatric surgeon in AIC Kijabe Mission } \\ \text { Hospital, Chief Executive Officer of the } \\ \text { hospital \& surgeon of the Bethany kids } \\ \text { program }\end{array} \\ \text { Dr. Stanley Mugambi } & \begin{array}{l}\text { Consultant Pediatric surgeon and lecturer } \\ \text { in the Aga khan university Hospital }\end{array}\end{array}$

Dr. Peter Mwika Consultant pediatric surgeon \& lecturer in the UON with interests in pediatric urology

Dr. SwalehShahbal Consultant surgeon and lecturer in the UON with interests in pediatriclaparoscopy

Dr. FarihaFazal Consultant General and pediatric surgeon with interests in neonatal surgery.

Dr. SusaneNabulindo Consultant pediatric anesthesiologist and a lecturer in the UON

AIC- Africa Inland Church, KAPS- Kenya Association of Paediatric Surgeons, KNH- Kenyatta National Hospital, UONUniversity of Nairobi of ARM with the aim of the latter giving hope to the former

\section{Conclusion}

In conclusion the KAPS conference 2017 aimed to demystify Anorectal malformations to healthcare providers and parents of children with the condition. The participants were empowered with both skills and knowledge in the management of ARM specifically on the approach to diagnosis, initial assessment of ARM variants and the principles of surgical repair. Notably, the social challenges faced by the families of children with ARM were highlighted as a major plight in the management of this condition this inspired the formation of the Kenya ARM Working Group (KAWG) which will be officially launched in the next conference slated for November2018.

\section{Acknowledgments}

1. Kenyatta National Hospital

2. University of Nairobi

3. AIC Kijabe Mission Hospital

4. Kenya Association of Paediatric Surgeons

5. Standard Media group

6. The Nairobi Hospital

\section{References}

1. Swaleh S. Quality of Life in Children after Corrective Surgery for Anorectal Malformation at Kenyatta National Hospital.(Master's thesis on the internet). Nairobi: University of Nairobi; 2016. Available from: http://erepository.uonbi.ac.ke/handle/11295/99009

2. Beudeker N, Broadis E, Borgstein E, Heij et al. The Hidden Mortality of Imperforate Anus.Afr J Paediatr Surg. 2013; 10(4):302-6.

3. Gama M, Tadesse A. Management of Anorectal Malformation: Experience from Ethiopia Ann Afr Surg. 2018; 15(1):25-28

4. Matambo L. KTN LEO (Television broadcast) Nairobi: Standard Group Center; 2017 Nov 8th. Hospitali-yatoa-huduma-kwa-watoto-waliozaliwabila-ya-njia-ya-choo. Available from: https://www.standardmedia.co.ke/ktnnews/video/20 00143409 
5. Juma T. The Utility of Transperineal Ultrasound in Anorectal Malformation: A Cross-Sectional Analytical Study at The Kenyatta National and Referral Hospital (Master's thesis on the internet). Nairobi: University of Nairobi;2016. Available from:

http://erepository.uonbi.ac.ke/handle/11295/99440 